\title{
Increased Knowledge and Awareness of Celiac Disease will Benefit the Elderly
}

\author{
Aaron Lerner ${ }^{1,2, *}$, Torsten Matthias ${ }^{1}$ \\ ${ }^{1}$ AESKU.KIPP Institute, Mikroforum Ring 2, Wendelsheim 55234, Germany. \\ ${ }^{2}$ B. Rappaport School of Medicine, Technion-Israel Institute of Technology, Michal St, No 7, Haifa, 34362, Israel \\ *Corresponding author: aaronlerner1948@gmail.coml
}

Received July 30, 2015; Revised August 01, 2015; Accepted August 06, 2015

\begin{abstract}
Celiac disease, once deemed to be primarily a pediatric disease, is accepted nowadays as a lifelong disease that increasingly affects the elderly. In older patients it is late and underdiagnosed, it is hypo- or asymptomatic and case finding strategy is recommended. Gluten restrictive therapy is problematic but manageable and beneficial, improving symptoms, serology, histology and preventing complications. Increased knowledge and awareness on $\mathrm{CD}$ in the third age and a comprehensive, multidisciplinary and holistic approach will improve their outcome.
\end{abstract}

Keywords: celiac disease, elderly, clinical presentation, diagnosis, therapy, complication, awareness

Cite This Article: Aaron Lerner, and Torsten Matthias, "Increased Knowledge and Awareness of Celiac Disease will Benefit the Elderly.” International Journal of Celiac Disease, vol. 3, no. 3 (2015): 112-114. doi: 10.12691/ijcd-3-3-6.

\section{Introduction}

Aging and the accompanying decline of physiological processes has substantial effect on gastrointestinal functions, implicating diagnosis, management and outcome. Celiac disease (CD) is only one of those conditions. Major problems exist in the clinical assessment of CD in the elderly [1]. The case report presented by Deleanu et al. brings-up multiple diagnostic, and assessments facets in dealing with the unique aspects of CD in the third age. The 62y old patient presented with ischemic cardiomyopathy, left ventricular failure, asthma, osteoporosis, iron and magnesium deficiencies and depression. Fortunately enough a rapid diagnosis of CD and gluten free diet were implemented for the benefit of the patient. The patient represents a growing sector of the population having multiple problematic aspects when facing $\mathrm{CD}$. The present editorial will expand on those age specific, gluten related, and unique aspects. The aim being, to increase knowledge and awareness of the professionals for the benefit of the affected elderly.

\section{Late and Underdiagnosed}

Historically, CD was once deemed to be primarily a pediatric disease, but nowadays, it is accepted as a lifelong disease that may affect and present at any age. In contrary to the expanded knowledge on the disease in the first half of life, very little is known about CD in elderly populations, summarized in recent years by several groups $[2,3,4,5,6]$. The disease is underdiagnosed. According to several studies only $4.4-12.4 \%$ of patients were diagnosed at or above 50 years of age [3,7,8,9]. Gasbarrini et al demonstrated that $40 \%$ of elderly patients were diagnosed at >65 years, the mean diagnostic delay was 17 years ranging from 0 to 58 years [3]. Concerning the prevalence of CD in the elderly, the topic is controversial. While in some of the studies, higher elderly prevalence was reported contradicting the studies with higher pediatric CD prevalence [10].

Yes, the diagnosis is late, the delay from onset of symptoms to diagnosis being $8-17$ years [3,4,5,7]. Interestingly, in a biopsy-defined finish study design, the disease was more frequently depicted in the elderly group, compared to a younger population [11]. A year later, the same group indicated that repeated evaluation in the elderly may detect new cases that developed later in life [12]. The following reasons are suggested to explain the under/late diagnosis [4]:

1. Limited mucosal extent of the disease, minimizing symptomatology.

2. The cognitive impairment may hide the presenting symptoms.

3. Low index of suspicion by the care-giver, delaying the work-up.

4. Additional environmental precipitating factors may accumulate with the advancement of age.

5. Seronegativity might develop with increasing age, masking serological detection $[13,14]$.

6. The latent $\mathrm{CD}$, documented in the elderly, might impact underllate detection of CD [4].

7. Paucity or non-specific clinical presentation or findings [5].

8. Common symptoms and clinical signs in the third age of life, such as fatigue, weight loss, decreased appetite, 
mood changes and anemia overlap CD presentations, but the care-giver will direct the work-up toward a more morbid, life threatening conditions, generally a more costly one.

The multiple potential explanations witness our lack of understanding of the late age-dependent autoimmunogenesis in general and in CD in particular.

\section{Problematic Presentations}

The clinical presentation of CD changes across the life span. As people age they present progressively less common major clinical indicators such as diarrhea, malabsorption, weight loss, protuberant abdomen, nutritional deficiencies and positive serology.

The mode of presentation of CD in the elderly is controversial. While some reported less prominent gastrointestinal manifestations such as bloating as opposed to classical malabsorption and chronic diarrhea features, others have not reported such differences $[3,4,7,8,9,15]$. Reduced bone health, manifested as osteopenia/porosis and fractures was increasingly described as comorbidity [16] and iron deficiency anemia is very prevalent in the elderly CD patients [17]. A most recent Australian study analyzing CD patients at routine upper endoscopy, shed a more realistic light on older patients [18]. At least $10 \%$ of new cases are likely to be underdiagnosed at routine gastroscopy, particularly patients above 60 years who more commonly present with atypic symptoms. 28\% of the newly diagnosed CD patients were aged over 60 years. In order to improve identification, it was suggested to perform pre-endoscopy celiac serology.

\section{Problematic but Manageable and Beneficial Therapy}

A life-long gluten-free diet is restrictive, increasing the burden of the illness and impairing life quality. In the elderly, where adaptation to dietary habits are life-long deeply imbedded and hard to disrupt, the diet may not be tolerated. Limited financial and social resources, decreased mobility, difficult access to gluten-free products, impaired vision, cognitive decline and poor nutritional intakes are some of the problems that the elderly may confront [6]. Despite the above problematic aspects, it should be noted that patients might benefit and have dramatic improvement on gluten restrictive nutritional therapy $[8,17,19]$. Recently, it was shown that the compliance to gluten-free diet is very good, iron deficient anemia is restored, other nutritional deficiencies and bone mineral density ameliorate, gastrointestinal symptoms, though subtle, were alleviated and histological or serological recovery was virtually complete, in screendetected older CD patients [19]. Older age should not be a barrier to dietary therapy. Still, due to special needs and increased morbidity of the older CD patients, a comprehensive, multidisciplinary and holistic approach will improve their outcome.

Finally, the screening methodology to detect CD in the elderly is debatable. However, more authors favor case finding $[4,10,19,20,21]$ rather than mass screening $[16,22]$.
Most recently, reviewing the screening methodology of $\mathrm{CD}$ in the high-risk population, the elderly were not mentioned [23]. It seems that the available knowledge and the recent literature favor including this under privileged high-risk population for active serological screening, mainly if symptomatic, having positive serology, comorbid autoimmunity, family history or other high index of suspicion.

Recently, 10 things that every gastroenterologist should know about CD were published [24]. Using the same coin, Table 1 summarizes the 10 commandments that every professional, dealing with the elderly population, should know.

Table 1. 10 things that every CD professional should know about celiac disease in the elderly

\begin{tabular}{|l|l|}
\hline & Things to know \\
\hline $\mathbf{1}$ & Prevalence is increasing \\
\hline $\mathbf{2}$ & Medical awareness is low \\
\hline $\mathbf{3}$ & Late and underdiagnosed \\
\hline $\mathbf{4}$ & Nonspecific, minimally or asymptomatic presentations \\
\hline $\mathbf{5}$ & Increased morbidity and complications \\
\hline $\mathbf{6}$ & Elderly are a high-risk population \\
\hline $\mathbf{7}$ & Active case-finding is warranted by serology and endoscopy \\
\hline $\mathbf{8}$ & Gluten restriction is feasible and beneficial \\
\hline $\mathbf{9}$ & Early and correct diagnosis prevent CD associated complications \\
\hline $\mathbf{1 0}$ & \begin{tabular}{l} 
Comprehensive, multidisciplinary approach will improve their \\
\hline
\end{tabular} \\
\hline
\end{tabular}

\section{Conclusions}

CD is late and underdiagnosed in the elderly population for multiple reasons. Despite paucity of symptoms and findings, it is becoming increasingly recognized in this unique age, presenting comorbidity and complication. Most probably, case finding serological and endoscopic active strategies will improve the diagnosis rate. Older age is not a barrier to gluten restricted diet, on the contrary, it induces recovery to normal in most of the clinical, serological and histological aspects.

\section{References}

[1] Deleanu D, Muntean A, Baican A, Danciu P, Magurici C, Samasca G. Major problems to the clinical reassessment of celiac disease in elderly. International Journal of Celiac Disease.2015; 3: 110-111.

[2] Tai V, Crowe M, O'Keefe S. Celiac disease in older people. J Am Geriatric Soc. 2000; 48:1690-6.

[3] Gabardine G, Ciccocioppo R, De Vitis I, Corazza GR; Club del Tenue Study Group. Coeliac Disease in the Elderly. A multicentre Italian study. Gerontology. 2001;47:306-10.

[4] Freeman HJ. Adult celiac disease in the elderly. World J Gastroenterol. 2008;14:6911-4.

[5] Lurie Y, Landau DA, Pfeffer J, Oren R. Celiac disease diagnosed in the elderly. J Clin Gastroenterol. 2008;42:59-61.

[6] Rashtak S, Murray JA. Celiac disease in the elderly. Gastroenterol Clin North Am. 2009;38:433-46.

[7] Singh P, Shergill S, Makharia GK. Celiac disease in older adults. J Gastrointestin Liver Dis. 2013;22:359-60.

[8] Casella S, Zanini B, Lanzarotto F, Villanacci V, Ricci C, Lanzini A. Celiac disease in elderly adults: clinical, serological, and histological characteristics and the effect of a gluten-free diet. J Am Geriatr Soc. 2012;60:1064-9. 
[9] Mukherjee R, Egbuna I, Brar P, Hernandez L, McMahon DJ, Shane EJ, et al. Celiac disease: similar presentations in the elderly and young adults. Dig Dis Sci. 2010;55:3147-53.

[10] Almeida LM, Castro LC, Uenishi RH, de Almeida FC, Fritsch PM, Gandolfi L, et al. Decreased prevalence of celiac disease among Brazilian elderly. World J Gastroenterol. 2013;19:1930-5.

[11] Vilppula A, Collin P, Mäki M, Valve R, Luostarinen M, Krekelä I, et al. Undetected coeliac disease in the elderly: a biopsy-proven population-based study. Dig Liver Dis. 2008;40:809-13.

[12] Vilppula A, Kaukinen K, Luostarinen L, Krekelä I, Patrikainen H, Valve R, et al. Increasing prevalence and high incidence of celiac disease in elderly people: a population-based study. BMC Gastroenterol. 2009;9:49.

[13] Salmi TT, Collin P, Korponay-Szabó IR, Laurila K, Partanen J, Huhtala $\mathrm{H}$, et al. Endomysial antibody-negative coeliac disease: clinical characteristics and intestinal autoantibody deposits. Gut. 2006;55:1746-53.

[14] Dahle C, Hagman A, Ignatova S, Ström M. Antibodies against deamidated gliadin peptides identify adult coeliac disease patients negative for antibodies against endomysium and tissue transglutaminase. Aliment Pharmacol Ther. 2010;32:254-60.

[15] Quinn CJ, Cotter PE, Stevens FM, O’Keeffe ST. Coeliac disease in the older patient. Rev in Clin Gerontol 2006;16:291-300.

[16] Godfrey JD, Brantner TL, Brinjikji W, Christensen KN, Brogan DL, Van Dyke CT et al. Morbidity and mortality among older individuals with undiagnosed celiac disease. Gastroenterology. 2010;139:763-9.
[17] Hankey GL, Holmes GKT. Coeliac disease in the elderly. Gut 1994;35:65-67.

[18] Robson K, Alizart M, Martin J, Nagel R. Coeliac patients are undiagnosed at routine upper endoscopy. PLoS One. 2014;9:e90552.

[19] Vilppula A, Kaukinen K, Luostarinen L, Krekelä I, Patrikainen H, Valve R, et al. Clinical benefit of gluten-free diet in screendetected older celiac disease patients. BMC Gastroenterol. 2011;11:136.

[20] Freeman HJ. Small bowel mucosal biopsies for case-finding in celiac disease. International Journal of Celiac Disease 2015;3:5052.

[21] Lerner A, Neidhöfer S, Matthias T. Serological markers and/or intestinal biopsies in the case-finding of celiac disease. International Journao of Celiac Disease. 2015;3:53-55.

[22] Katz KD, Rashtak S, Lahr BD, Melton LJ 3rd, Krause PK, et al. Screening for celiac disease in a North American population: sequential serology and gastrointestinal symptoms. Am J Gastroenterol. 2011;106:1333-9.

[23] Ludvigsson JF, Card TR, Kaukinen K, Bai J, Zingone F, Sanders DS, et al. Screening for celiac disease in the general population and in high-risk groups. United European Gastroenterol J. 2015;3:106-20.

[24] Oxentenko AS, Murray JA. Celiac Disease: Ten Things That Every Gastroenterologist Should Know. Clin Gastroenterol Hepatol. 2015;13:1396-404. 